\title{
A Review of Secondary Aluminum Production and Its Byproducts
}

\author{
SAI KRISHNA PADAMATA, ${ }^{1}$ ANDREY YASINSKIY (D),,${ }^{1,2,3}$ \\ and PETER POLYAKOV ${ }^{1}$ \\ 1.- Laboratory of Physics and Chemistry of Metallurgical Processes and Materials, Siberian \\ Federal University, Krasnoyarsk, Russia 600025. 2.-IME Process Metallurgy and Metal \\ Recycling, RWTH Aachen University, Intzestraße 3, 52056 Aachen, Germany. \\ 3.—e-mail: ayasinskiykrsk@gmail.com
}

\begin{abstract}
Secondary aluminum production is required for the conservation of the environment. It can significantly reduce greenhouse gas emissions and energy consumption and reduce the consumption of alumina, a source of primary aluminum. Secondary aluminum production requires sorting processes for the metal scrap before starting the refining process. Salt slags generated from both primary and secondary aluminum production need to be recycled/treated as they are considered hazardous byproducts. This review paper discusses the methods used for sorting and refining aluminum waste and managing and utilizing slag cakes/slag from recycling techniques.
\end{abstract}

\section{INTRODUCTION}

Aluminum is the second most-consumed metal in the world, only outranked by steel. Primary aluminum is produced through the Hall-Heroult process. ${ }^{1}$ In this process, alumina dissolves in a sodium cryolite melt, and aluminum is reduced at the aluminum liquid cathode pool while the anode products are significant amounts of $\mathrm{CO}_{2}$ and other greenhouse gases. ${ }^{2}$ Production of primary aluminum involves high energy consumption and emission of high volumes of $\mathrm{CO}_{2} \cdot{ }^{3}$ About $93 \%$ of the $\mathrm{CO}_{2}$ emissions can be reduced through the recycling of aluminum waste. ${ }^{4}$ Although significant effects have been made to minimize pollution by replacing consumable carbon with inert anodes, a suitable material is yet to be found which can be used at an industrial scale. ${ }^{5}$ On the other hand, recycling aluminum from sources such as process and commercial scraps, household wastes, foils, and aluminum coatings could be environmentally and economically beneficial. Aluminum recycling could reduce bauxite consumption, which is used as the primary raw material for the production of primary aluminum. Secondary aluminum production (SAP) requires nearly 10 to 15 times less energy than

(Received April 6, 2021; accepted June 30, 2021;

published online July 30, 2021) primary aluminum production. ${ }^{6}$ Recycling scrap metal could be advantageous, resulting in the conservation of aluminum resources and reducing the costs related to waste landfilling. SAP would benefit the countries that rely entirely on imports of primary aluminum. They can utilize the scrap materials to recover aluminum and accommodate the demand for the metal to a certain extent. The prominence of SAP has been growing throughout the world as the demand for aluminum and the generation of aluminum scrap has been exponential.

It is well known that most of the aluminum produced from scrap has a significant amount of impurities and cannot be used in applications such as foil for capacitors and disk blanks. ${ }^{7}$ The production of high purity secondary aluminum through the Hoopes process requires more energy $(17-18 \mathrm{kWh} /$ $\mathrm{kg}$ ) than the production of primary aluminum (14 $\mathrm{kWh} / \mathrm{kg}){ }^{8}$ Secondary aluminum can be used in many of the applications where primary aluminum is utilized. According to studies conducted by the European Aluminum Association (EAA), post-consumer aluminum available for the recycling process could more than double by 2050 in Europe: from 3.8 million tons per year to 8.6 million tons per year. ${ }^{9}$ The feedstock required for SAP is growing and could result in more than $50 \%$ SAP of the total aluminum produced in a year across the world. Accumulation of unwanted elements in the secondary aluminum is 
a growing concern, and strategies designed to mitigate the unwanted elements are necessary. ${ }^{10-12}$ Two solutions have been widely proposed to deal with contaminated secondary aluminum: (a) dilution of the secondary aluminum with the primary product to reduce the contamination levels (the negative aspect of this process is that it could limit the production of secondary aluminum), and (b) down-cycling, where the alloys are produced of lower quality (but this could lead to economic problems for secondary production). ${ }^{7}$ The main steps involved in the recovery of aluminum are (a) physical separation which involves methods like magnetic separation, air separation, eddy currents, sink/float separation, and color sorting; and (b) the refining process, which has methods like the Hoopes process, fluxes, gas fluxing, etc. Figure 1 ties together the various recovery processes used for SAP.

This paper aims to give an overview of advances in the techniques/steps involved in aluminum recovery. The recycling methods related to the recovery of aluminum from scrap separation to refining techniques will be included, and new electrochemical techniques that are being implemented to attain high-quality products. An overview of salt slag, which is the main byproduct of SAP, will be provided, as it is considered highly toxic and requires special attention.

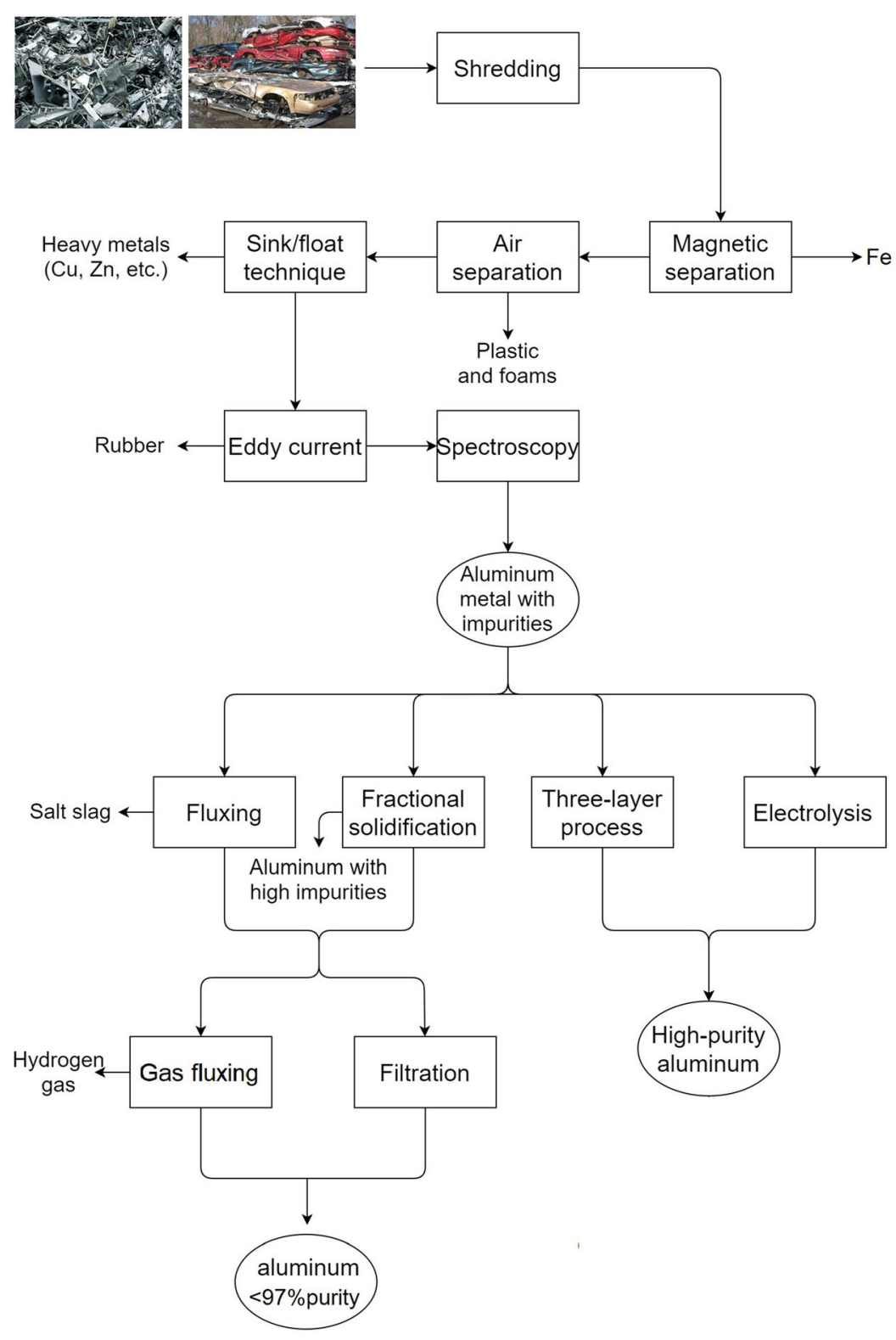

Fig. 1. Flowsheet of aluminum recovery using various recovery processes from scrap. 


\section{SEPARATION TECHNIQUES}

The separation stage is the primary step involved in SAP. This stage is used to remove metallic residues such as $\mathrm{Fe}, \mathrm{Mg}, \mathrm{Cu}$, and $\mathrm{Zn}$ and nonmetallic ones like rubber, glass, and plastics. Before the scrap materials reach recycling plants for the separation process, the automobiles, household waste, and electronics scraps are shredded into pieces. A preheating method is mainly used for household waste, such as cans, to remove plastic coatings or organic paints before the remelting process. The type of sorting technique implemented to remove the residue depends upon the residue type. The following are the four main separation techniques widely used in SAP.

\section{Magnetic Separation}

Magnetic separation is implemented to separate ferrous and non-ferrous metal scrap. This method is extensively used in SAP. In this process, scrap is placed on a conveyor which passes near a second conveyor equipped with a $\mathrm{NdFeB}$ magnet. The ferromagnetic materials (iron and steel) present in the scrap attach to the magnet and are pulled away by the second conveyor, while the non-ferrous materials fall into a container provided for collection. The main limitation of the process is that only ferrous metals can be separated from the scrap mixture and further separation techniques need to be performed to remove non-ferrous materials like rubber, plastic, magnesium, copper, etc. ${ }^{13}$

\section{Air Separation}

Lightweight materials such as rubber, plastics, and foams can be removed from the scrap using the air separation method. The recycling material stream is fed into the vertical air separation system through a column having the air pushing upwards. The light materials are further pushed upwards using various feeds while the heavy ones are collected at the bottom. The main disadvantage is that lightweight metal components such as soda cans and foils are also separated along with the unwanted impurities, causing metal loss. ${ }^{13}$ In addition, the impurities collected in this process are landfilled. Currently, this sorting technique is not widely used but it is expected to be adopted by most recycling plants to obtain metallic scrap streams. ${ }^{14}$

\section{Sink/Float Method}

In this method, a liquid bath containing a fine suspension of water and magnetite is used to separate materials with differing densities. The scrap metal stream after the magnetic and air separations includes impurities such as zinc, magnesium, copper, and higher density plastic and rubber. Because these materials have different densities (see Table I), the sink/float technique can be applied to separate aluminum from unwanted
Table I. Densities of components present in aluminum scrap ${ }^{16}$

\begin{tabular}{lc}
\hline Material & Density $\mathbf{g ~ c m}$ \\
\cline { 3 - 3 } Foams & $0.01-0.6$ \\
Rubber & $0.8-0.9$ \\
Plastic & $0.9-1.4$ \\
Magnesium & $1.7-1.9$ \\
Aluminum & $2.6-2.9$ \\
Zinc & $5.2-7.2$ \\
Stainless steel & $7.5-8.0$ \\
Copper & $7.5-9.0$ \\
Lead & $10.6-11.5$ \\
\hline
\end{tabular}

residue. The process contains three steps. The nonmetallic materials (foams, rubber, and plastic) are separated from the metals in water (with a specific density of 1) in the first step. In the second step, a slurry with a specific density of 2.5 is used to separate magnesium from other metals. In the final stage, slurry with a specific density of $3.2-3.5$ is used to separate aluminum from the rest of the metals. The specific density of the slurry is managed by adjusting the quantity of magnetite in the liquid. ${ }^{15}$ The main disadvantages of this technique include high maintenance, loss of boat-shaped metals, and it is not possible to sort aluminum 2000 series from 3000 and 5000 series.

\section{Eddy Current}

Eddy current separation (ECS) is used to separate non-ferrous metals from other particles. In ECS, an alternative eddy current is induced in the nonferrous metals when met with a variable magnetic field generated by the rotating $\mathrm{NdFeB}$ drum magnets. The newly developed magnetic field of the electrically conductive non-ferrous metals and the magnetic field of the eddy current separator have the same magnetic field direction. This phenomenon results in the repulsion of non-ferrous metals, changing the movement of the metals and separating them from other particles. Metals with different eddy currents are thrown different distances due to their varying electric conductivity and density. The metals can be separated by placing the collectors at different distances from the rotor. ${ }^{17}$ The main shortcoming of this method is the difficulty in removing foils and tiny metallic wires as it is challenging to generate a magnetic field in them. The separation efficiency of this method mainly depends on three factors: feeding speed, $\omega R-v$, and $\frac{S_{p}}{S_{m}}$. Here, $\omega R-v$ is the distance between the feed speed and rotation speed of the magnetic field; and $\frac{S_{p}}{S_{m}}$ is the ratio between the maximum cross-area of the metallic flake and the magnet side area facing the particles. The detachment angle increases with an increase in $\omega R-v$ and the separation efficiency 
increases with increasing detachment angle. Separation efficiency increases with increasing $\frac{S_{p}}{S_{m}}$. The studies conducted by Ruan et al. ${ }^{18}$ suggest that complete aluminum separation from wastes can be achieved when the feed speed is $0.5 \mathrm{~m} . \mathrm{s}^{-1}$, the detachment angle is greater than $6.61 \mathrm{deg}$, and $\frac{S_{p}}{S_{m}}$ is between 0.08 and 0.51 . No pollution is generated from this method. Figure 2 shows the separation mechanism of scrap materials using an eddy current separator.

\section{Spectroscopy Techniques}

The spectrographic technique is widely used in sorting aluminum scrap at an industrial level. The most common techniques are laser-induced breakdown spectroscopy (LIBS), x-ray fluorescence (XRF), and gamma-ray fluorescence. The composition of metal elements in the scrap can be identified by using these techniques, which can enable the separation of the scrap mixture. The gamma-ray fluorescence uses neutron flux. However, the method is not commercialized as it requires a long neutron flux exposure on the scrap material for neutron activation, due to its limited intensity.
In the LIBS method, a pulse laser hits the surface of the scrap material, resulting in the generation of hot plasma. ${ }^{19}$ The emitted light is detected by a photodiode detector and a polychromator which sends the signal to a recording instrument, followed by directing the scrap metal into an appropriate bin using a mechanical arm. The pulse laser can only penetrate a small distance. Therefore, it would be difficult to detect the chemical composition of the strip metal with oil, coating, or even the oxide layer. The recent advancements in this technology led to overcome this issue. ${ }^{20,21}$

In the XRF technique, a diverging x-ray beam (with high energy $0.1-100 \mathrm{keV}$ ) is projected onto the surface of the targeted material, resulting in x-ray fluorescence radiation. The radiation occurs due to the atom's ionization, meaning that the electron is removed from the inner shell and the higher energy shell releases the hole. The energy difference is released in the form of radiation which is detected by a solid-state photocathode detector. A multivariate calibration procedure is implemented to characterize the energy peaks recorded to obtain the elemental concentrations of the scrap material. ${ }^{22}$ This technique is used at the industrial level, although the major disadvantage of this method is (a)

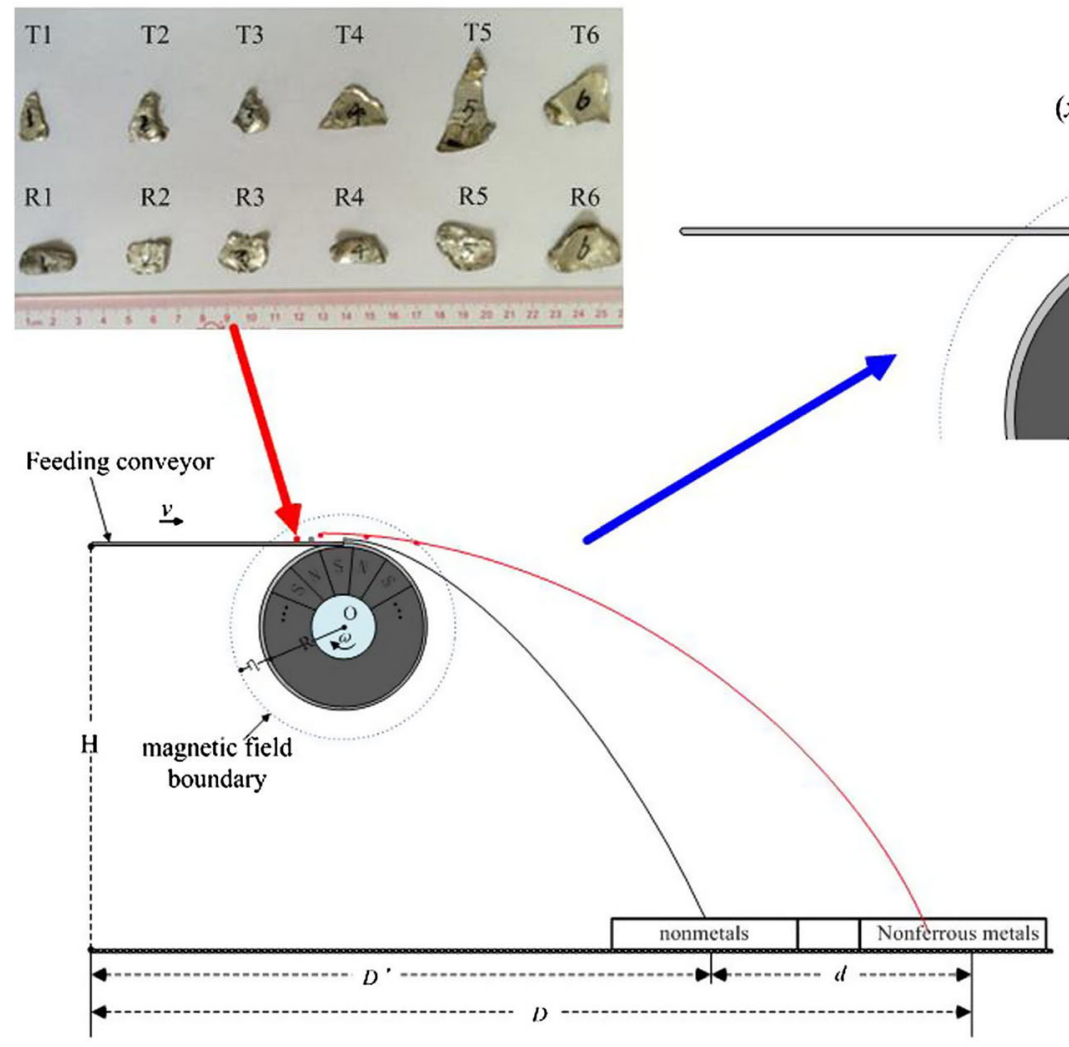

(b) (c) 
that it is difficult to analyze the accurate concentration of aluminum alloys containing low atomic number elements such as lithium, beryllium, boron, or magnesium. ${ }^{21}$

The techniques mentioned above are extensively used to separate scrap materials to obtain highquality aluminum scrap for the refining process. However, the sequence and the processing methodology may vary depending upon the scrap material type and quality of produced secondary aluminum.

\section{ALUMINUM REFINING}

Aluminum refining involves the removal of dissolved impurities present in the aluminum scrap metal. Researchers aim to find energy-efficient as well as environmentally friendly methods for aluminum refining. The most popular method used for aluminum refining is fluxing, while there has been a recent focus on electrolysis methods such as lowtemperature electrolysis and the thin-layer refining process. The selective melting technique is generally used on aluminum scrap metals containing weld joints with metals such as $\mathrm{Sn}\left(232^{\circ} \mathrm{C}\right), \mathrm{Pb}$ $\left(327^{\circ} \mathrm{C}\right)$, and $\mathrm{Zn}\left(419^{\circ} \mathrm{C}\right)$ having lower melting temperatures than aluminum $\left(660^{\circ} \mathrm{C}\right)$. The furnace temperature is set to the melting temperature of the metals mentioned above, and the contaminants are removed before finally recovering the aluminum metal.

\section{Remelting and Fluxing}

In the remelting process, pure aluminum is initially heated at around $800^{\circ} \mathrm{C}$, followed by the addition of metal scrap. It is sometimes challenging to maintain the operating temperature as cold scrap metal is fed in periodically. The dross on top of the metal bath is skimmed continuously. In Eggen et al., ${ }^{23}$ the remelting process was performed to recover aluminum from household waste (cans and foils). Pre-treatment, such as thermal decoating, compacting, and sizing was performed on household waste before remelting. Decoating temperatures were $300^{\circ} \mathrm{C}$ and $550^{\circ} \mathrm{C}$ and were held till the process was complete (till the smoke stopped). Decoating cans at $550^{\circ} \mathrm{C}$ compared with $300^{\circ} \mathrm{C}$ produced higher yield, low $\mathrm{Mg}$ and $\mathrm{Pb}$ content, and cleaner melt with a low oxide scale inclusion area. While cans can be recycled with acceptable yield and metal quality, foils had a negative yield and cannot be recycled.

Nakajima et al. ${ }^{24}$ conducted a thermodynamic simulation study to estimate the possibility of the removal of an impurity element $(M)$ through the remelting process. The 45 elements that are most commonly found in scrap metal were studied to understand their equilibrium distribution ratios among metals, slag, and gas phase. The distribution of impurity elements among molten metal and oxide slag can be quantified by equilibrium constants of oxidation and evaporation processes. The distribution coefficient determines the removal of impurities from the solvent metal. For oxidation of $M$ from the solvent metal, reaction (1) takes place:

$$
m M+\frac{n}{2} O_{2}=M_{m} O_{n}
$$

where the equilibrium constant $K^{\prime \prime}$ is given by Eq. 2

$$
K^{\prime}=\frac{a_{M_{m} O_{n}}}{a_{M_{m}} P_{O_{2}}^{\frac{n}{2}}}=\frac{\gamma_{M_{m} O_{n}} x_{M_{m} O_{n}}}{\left(\gamma_{M} x_{M}\right)^{m} P_{O_{2}}^{\frac{n}{2}}}
$$

where $P_{O_{2}}$ is the oxygen partial pressure $(\mathrm{Pa})$, $a_{M_{m} O_{n}}, \gamma_{M_{m} O_{n}}$, and $x_{M_{m} O_{n}}$ are the activity in the Raoultian standard state (pure solid oxide); the activity coefficient; and the mole fraction of oxide $\mathrm{M}_{\mathrm{m}} \mathrm{O}_{\mathrm{n}}$ distributed into slag phase by oxidation.

By rearranging Eq. (2), the distribution ratio of $M$ between slag and metal can be obtained:

$$
L^{\prime}=\frac{x_{M}}{x_{M_{m} O_{n}}}=\frac{\gamma_{M_{m} O_{n}}}{K^{\prime} \gamma_{M}^{m} x_{M}^{m-1} P_{O_{2}}^{\frac{n}{2}}}
$$

In the case of $M$ evaporation from solvent metal:

$$
M=M(g)
$$

The equilibrium constant is defined by the following equation:

$$
K=\frac{P_{M}}{a_{M}}=\frac{P_{M}}{\gamma_{M} x_{M}}=P_{M}^{o}
$$

where $P_{M}^{o}, P_{M}, a_{M}, \gamma_{M}$ and $x_{M}$ are the partial pressure of pure element $M(\mathrm{~Pa})$, partial pressure of $M$ in the alloy $(\mathrm{Pa})$, the activity of $\mathrm{M}$ in the Raoultian standard state (a pure liquid substance), the activity coefficient of $M$, and the mole fraction of $M$, respectively.

The distribution coefficient of $\mathrm{M}$ between metal and gas phase is as follows:

$$
L^{\prime \prime}=\frac{P_{M}}{P_{A l}}=\frac{P_{M}^{o} \gamma_{M} x_{M}}{P_{A l}}
$$

A smaller $L^{\prime}$ value corresponds to easier removal of $\mathrm{M}$ into the slag phase by oxidation and larger values of $L^{\prime \prime}$ result in easier removal of $M$ by evaporation.

Figure 3 shows the distribution ratios of impurities in three different phases during the remelting process. The figure shows that $\mathrm{Mg}, \mathrm{Ca}$, and $\mathrm{Be}$ can be removed by oxidation and transferred to the slag, while $\mathrm{Zn}, \mathrm{Hg}$, and $\mathrm{Cd}$ can be evaporated. The other elements remain in the metal and are difficult to remove. In reality, aluminum recycling in industries is additionally affected by different parameters such as the fluidity of the metal bath, temperature distribution in the furnace, and non-uniformity of the gas phase.

Fluxing is the most commonly practiced technique for SAP. It is similar to the remelting process but with the addition of salt flux. In this process, a 


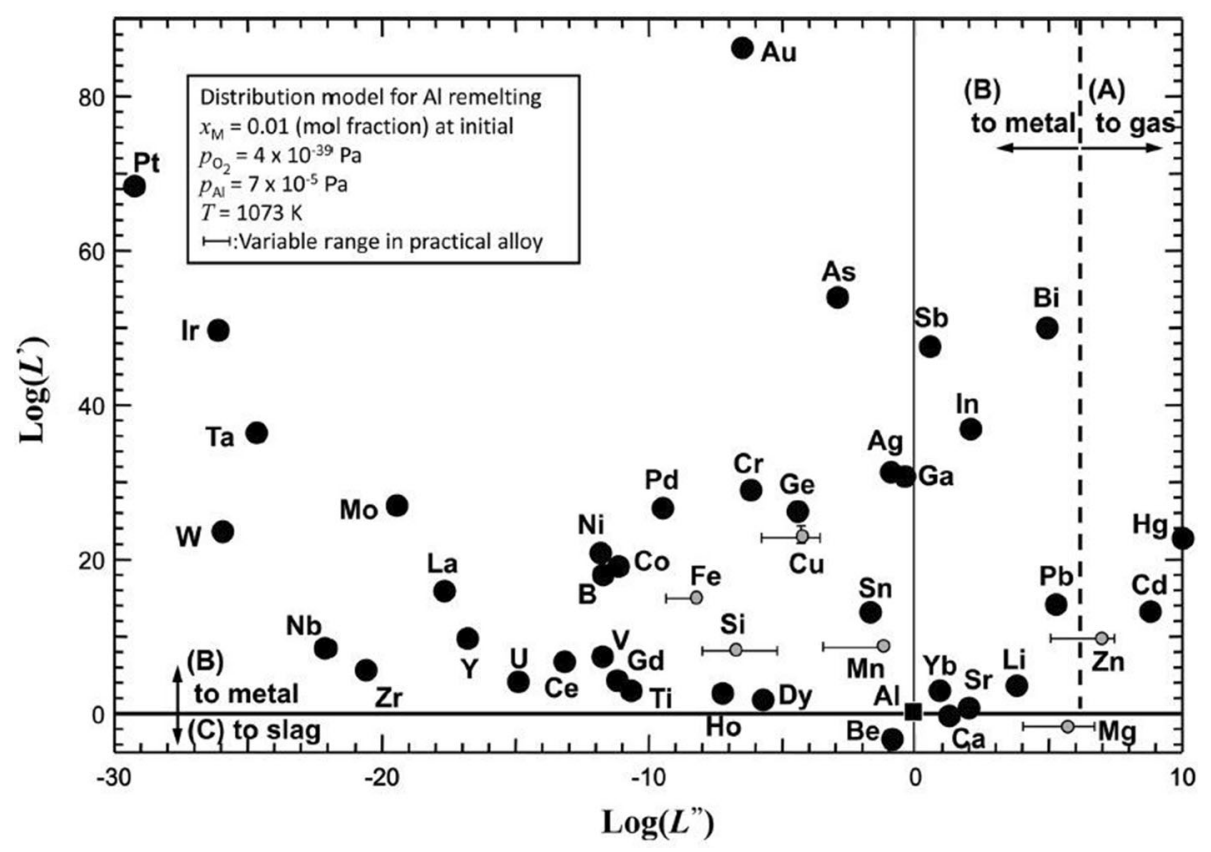

Fig. 3. Distribution of elements between metal, slag, and gas phases for simulated aluminum remelting. Reproduced with permission from Ref. 24.

high-temperature furnace is charged with molten salt used as flux, along with the scrap metal. The metal scrap is mechanically submerged as soon as possible to avoid metal oxidation and salt loss. The advantages of using this technique include (1) reduction of metal oxidation, (2) increased fluidity of the melt to encourage the separation of inclusions, (3) migration of impurities into the dross, and (4) removal of hydrogen and nitrogen gases from the liquid metal. The metallic impurities like $\mathrm{Mg}, \mathrm{Na}$, $\mathrm{Li}, \mathrm{Ca}$, etc. react with molten salt to form stable metallic chlorides which are removed in the form of a sedimented mixture or the dross, depending upon its density. ${ }^{25}$ Sodium chloride and potassium chloride are the most commonly used salts for fluxing due to their low melting point and low cost. ${ }^{26}$ $\mathrm{CaF}_{2}, \mathrm{NaF}$, and $\mathrm{Na}_{3} \mathrm{AlF}_{6}$ are the common fluoride salts used as additives in the flux to improve the coalescence of the metal. ${ }^{27-29}$ The salt flux promotes the stripping of the oxide layers on the aluminum metal, having a mechanism similar to the hot corrosion process, and improves coalescence between aluminum droplets. ${ }^{30}$ According to Roy and Sahai, ${ }^{31}$ the three steps involved in the stripping of the oxide layer from the liquid metal are: (1) openings developing in the oxide layer, (2) salt penetration between metal and oxide, and (3) oxide layer stripping and formation of dross/slag which improves metal yield.

In some cases, fluxing requires large volumes of salts to remove impurities. For instance, about 2.95 $\mathrm{kg}$ of salt is required to remove $1 \mathrm{~kg}$ of magnesium. Utigard et al. ${ }^{25}$ state that about $120 \mathrm{~kg}$ of chlorine gas is required to remove $\mathrm{Mg}$ from 1 metric ton of wrought 5XXX or 6XXX aluminum scrap metal. This would result in high amounts of chlorine and fluorine gas utilization, which must be captured and treated. The main advantage of fluxing over remelting is that the salt flux can break the thick oxide layer on the metal and improve metal coalescence. ${ }^{32}$

\section{Low-Temperature Electrolysis}

High purity aluminum was produced by Huan et al. through low-temperature electrolysis using a coarse Al-Si alloy as a dissolving anode $\left(170^{\circ} \mathrm{C}\right) .^{33}$ An Al-Si-based anode with the main impurities being $\mathrm{Fe}, \mathrm{Ca}, \mathrm{Ti}, \mathrm{Mg}$, and $\mathrm{Mn}$, and an aluminum sheet cathode were used in this method. The electrolyte composition by mass percentage was $\mathrm{AlCl}_{3}: \mathrm{NaCl}: \mathrm{KCl}=66: 20: 14$, and aluminum chloride was dried in a $\mathrm{HCl}$ atmosphere to reduce the moisture in the electrolyte. Potentiostatic electrolysis was performed between 0.3 and $0.7 \mathrm{~V}$. The electrochemical reduction potential of ions in the electrolyte was in the order $\mathrm{Fe}>\mathrm{Si}>\mathrm{Al}>\mathrm{Mg}>$ $\mathrm{Ca}$. At an electrode potential between 0.4 and $0.7 \mathrm{~V}$, $\mathrm{Fe}$ and $\mathrm{Si}$ dissolved electrochemically from the anode. In particular, the Si content (wt.\%) was around $0.77 \%$ in the reduced aluminum. At electrode potentials below $0.3 \mathrm{~V}$, only $\mathrm{Mg}, \mathrm{Ca}$, and $\mathrm{Al}$ were dissolved, while only aluminum was reduced at the cathode surface. Thus, aluminum purity of about 99.9\% was achieved when the electrode potential was at or below $0.3 \mathrm{~V}$. This technique can be used on impure aluminum alloys produced by the recycling process to obtain high-quality aluminum. 
The aluminum in the anode is dissolved in the electrolyte in the form of $A l_{2} C l_{7}^{-}$and $A l C l_{4}^{-}$while the electrodeposition of aluminum on the cathode is by the following reactions: ${ }^{34}$

$$
\begin{gathered}
4 \mathrm{Al}_{2} \mathrm{Cl}_{7}^{-}+3 e^{-} \rightarrow A l+7 \mathrm{AlCl} l_{4}^{-} \\
\mathrm{AlCl}_{4}^{-}+3 e^{-} \rightarrow A l+4 C l^{-}
\end{gathered}
$$

The current efficiency was around $94 \%$, and high aluminum purity can be attained at low energy consumption by using low-temperature electrolysis.

\section{Fractional Solidification}

In this process, the materials are processed in their semi-solid state with solutes separated between solid and liquid phases. In the case of aluminum scrap metals, the material is initially transformed into a liquid state followed by rapid cooling of the melt surface for the formation of aluminum crystals. These solidified pieces are deposited in the bottom of the furnace. If the solubility of the solutes (impurities) is higher in the liquid phase than in the solid phase, the aluminum crystals will reject the dissolved impurity enriching the liquid phase. Therefore, the liquid aluminum with high levels of impurities is removed while the solidified, high purity, aluminum remains in the furnace for remelting and is then removed. We can estimate the impurity removal level by considering the binary phase diagram and the thermodynamic distribution coefficient $(\mathrm{k})$. The equation proposed by Kahveci and Unal ${ }^{35}$ to estimate the thermodynamic distribution coefficient $(\mathrm{k})$ is as follows:

$$
k=\frac{C_{\text {soluteinsolid }}}{C_{\text {soluteinliquid }}}
$$

Here $C_{\text {soluteinsolid }}$ is the concentration of solute in the solid aluminum, and $C_{\text {soluteinliquid }}$ is the concentration of solute in liquid aluminum. For low values of $\mathrm{k}$, the impurities will migrate to the liquid

\begin{tabular}{|c|c|c|c|}
\hline Element & Range of $k$ & Element & Range of $k$ \\
\hline $\mathrm{Pb}$ & 0.0007 & $\mathrm{Mg}$ & $0.29-0.5$ \\
\hline $\mathrm{Ni}$ & $0.004-0.09$ & $\mathrm{Zn}$ & $0.35-0.47$ \\
\hline $\mathrm{Ca}$ & $0.006-0.08$ & $\mathrm{Mn}$ & $0.55-0.9$ \\
\hline $\mathrm{Na}$ & 0.013 & $\mathrm{~K}$ & 0.56 \\
\hline $\mathrm{Fe}$ & $0.018-0.053$ & $\mathrm{Sc}$ & 0.9 \\
\hline $\mathrm{Si}$ & $0.082-0.12$ & $\mathrm{Cr}$ & 1.8 \\
\hline $\mathrm{Sb}$ & 0.09 & $\mathrm{Zr}$ & $2.3-3$ \\
\hline $\mathrm{Cu}$ & $0.15-0.153$ & $\mathrm{~V}$ & $3.3-4.3$ \\
\hline $\mathrm{Au}$ & 0.18 & $\mathrm{Ti}$ & $7-11$ \\
\hline $\mathrm{Ag}$ & $0.2-0.3$ & $\mathrm{P}$ & $<0.01$ \\
\hline
\end{tabular}
aluminum. Table II shows the $\mathrm{k}$ values of various impurities in aluminum.
An example of the fractional solidification process can be found in Venditti et al., ${ }^{37}$ where the purification of different recycled aluminum alloys was performed. Three alloys were prepared by mixing $4500 \mathrm{~g}$ of aluminum (99.8\% purity) with $\mathrm{Al}-20$ wt.\% $\mathrm{Si}$, pure $\mathrm{Al}-13$ wt.\% Ni to obtain Al-3 wt.\% Si, Al-5 wt.\% $\mathrm{Cu}$, and $\mathrm{Al}-3$ wt.\% $\mathrm{Ni}$, respectively for the studies. The experimental setup was based on isothermal squeezing of the semi-solid alloy. The setup had three compartments where the bottom was the reservoir where the liquid aluminum with impurities was collected. The middle section was the furnace capable of holding up to $3000 \mathrm{~g}$ of melt. The furnace was open on both sides and the channel running through it was connected to a filter which was between the reservoir and the channel. The top part was a piston connected to a magnetostrictive transducer $(17.5 \mathrm{kHz})$. When the top part of the melt solidified, the piston pushed the melt and the impure liquid aluminum was pushed to the reservoir while the filter stopped the crystallized aluminum. It was suggested that the use of ultrasonic vibrations on the channel could enhance the purification efficiency. The experimental efficiency was up to $65 \%, 62 \%$, and $55 \%$ for $\mathrm{Al}-3$ wt. $\% \mathrm{Si}, \mathrm{Al}-5$ wt. $\% \mathrm{Cu}$, and $\mathrm{Al}-3 \mathrm{wt} . \% \mathrm{Ni}$, respectively, which was calculated using the following equation:

$$
E=100-\left(\frac{C_{\text {soluteinsolid }}}{C_{\text {soluteinoriginal }}} \times 100\right)
$$

\section{Hoopes Process}

In this three-layer process, the bottom layer constitutes a molten alloy of 60 wt.\% aluminum and $40 \mathrm{wt} . \%$ copper, which acts as an anode. The intermediate layer of molten electrolyte consists of fluoride or a mixture of fluoride-chloride salts, while the top layer, liquid aluminum, acts as a cathode. Their varying densities separate the three layers. Their densities at $750^{\circ} \mathrm{C}$ are $3.0 \mathrm{g.cm}{ }^{-3}$ for Al-Cu alloy, $2.7{\mathrm{~g} . \mathrm{cm}^{-3}}^{-}$for the molten electrolyte and 2.3 g.cm ${ }^{-3}$ for aluminum. The charged aluminum ions from the anode are reduced at the liquid aluminum. An ultra-high pure aluminum of $99.9999 \%$ can be produced from this three-layer process. $^{8}$ This process has a high energy consumption of around $17-18 \mathrm{kWh} . \mathrm{kg}^{-1}$ which is more than the traditional Hall-Heroult process.

\section{Gas Fluxing}

Hydrogen is the only gas with solubility in the aluminum melt, resulting in porosity in the solidified castings and ingots. The solubility increases with an increase in the temperature. ${ }^{38}$ The correlation between the solubility of hydrogen gas in aluminum and the temperature of molten aluminum is given by the below equation: ${ }^{39}$ 


$$
\log S=-\frac{2692}{T}+2.726
$$

$\mathrm{S}$ is the solubility of hydrogen gas (cc. $100 \mathrm{~g}^{-1}$ ) and $\mathrm{T}$ is the thermodynamic temperature (degree Kelvin). The solubility of hydrogen gas doubles for each $110^{\circ} \mathrm{C}$ increase in melt temperature.

The hydrogen gas, along with some inclusions and alkali can be removed using the gas fluxing process. In this process, gas (usually chlorine or argon) is injected at the bottom of the melt containing impurities. The hydrogen atoms and alkali diffuse on the bubble surface, resulting in the bubble's expansion by the hydrogen gas and the alkali. When the bubble reaches the surface, the hydrogen gas is released while the alkali migrates to the dross. In general, the gas is injected through a rotating impeller to increase the probability of collision between the gas bubbles and the inclusions. ${ }^{40}$ The degassing efficiency is $100 \%$ when the bubbles are saturated with hydrogen gas. However, as the hydrogen gas content drops, the pressure of the hydrogen decreases in the bubbles. This would require more inert anode gas pumping for the removal of low $\mathrm{H}_{2}$ concentrations from the metal. ${ }^{41}$ Equation (12) defines the gas removal ratio $(R)$, which is the volume of inert gas needed to remove 1 1 of hydrogen from the metal. At one atm pressure, $R$ for pure aluminum at $750^{\circ}$ is given as:

$$
R=\frac{(1-P)}{P}=\left(\frac{S . C}{H}\right)^{2}-1
$$

Here, $S$ is the solubility of hydrogen in molten metal, $P$ is the pressure of hydrogen vapor, $C$ is the correction factor, and $H$ is the amount of gas dissolved in molten metal. An increase in the melt temperature would increase the solubility of the hydrogen gas and gas removal ratio. Thus, the melt temperature should be lower to achieve high degassing efficiencies.

\section{Filtration}

Filtration is a mechanical process used to remove the inclusions when liquid metal is passed through a ceramic foam filter (CFF) which is the most common filter type used in aluminum production. The interaction between the inclusions and a filter surface is an important parameter, where selective capture of inclusions can be done through chemical bonding, friction, and electrostatic forces. For instance, $\mathrm{AlF}_{3}$ based filters could remove $\mathrm{Na}$ and $\mathrm{Mg}$ impurities from liquid aluminum by converting them to $\mathrm{NaF}$ and $\mathrm{MgF}_{2} \cdot{ }^{42}$ Inclusions and particles are stopped at the filter and accumulate, resulting in the formation of a cake, and the filtration ability improves when the cake gets thicker. High filtration efficiency can be achieved with better filter surface wettability, and the $\mathrm{SiC}$ foam filter showed better filtration efficiency than $\mathrm{Al}_{2} \mathrm{O}_{3}$ filters. $\mathrm{SiC}$ material has a lower wetting angle of 39 deg compared with
$\mathrm{Al}_{2} \mathrm{O}_{3}$ material with a wetting angle of $84 \mathrm{deg} .{ }^{43}$ The porosity and depth of the filters also influence the filtration efficiency. ${ }^{44}$ A liquid metal cleanliness analyzer (LiMCA) and porous disk filtration apparatus (PoDFA) are used to characterize the filtration efficiency of filters. ${ }^{45}$ The filtration efficiency of a CFF follows an exponential law as shown in Eq. (13), as verified in: ${ }^{46}$

$$
E_{0}=1-\exp \left(-\lambda_{0} L\right)
$$

where $E_{O}$ is the initial filtration efficiency, $\lambda_{0}$ is the initial filtration coefficient, and $L$ is the filter thickness.

Gauckler et al. ${ }^{47}$ described the influence of various filtration parameters on filtration efficiency; these are included in Table III.

The study conducted by Damoah and Zhang ${ }^{48}$ showed that a 30-ppi CFF can remove almost all inclusions with size $>125 \mu \mathrm{m}$ and up to $85 \%$ of inclusions with size $\approx 5 \mu \mathrm{m}$ from aluminum. Fluid dynamics modeling suggests that the larger inclusions are entrapped at the top-most part of the filter while the smaller ones are dispersed throughout the filter. The calculated interfacial energy between two colliding inclusions indicates that the particles exhibit a strong attraction force between them which holds the particles together. This explains why the small inclusions can be filtered during the process. The formation of intermetallic and nonmetallic inclusions bridges during filtration enhance the filtration efficiency by accumulating the finer inclusions. This attraction between the inclusions is only effective when the molten metal temperature is below $900^{\circ} \mathrm{C}$.

Other than CFF, a deep-bed filter (DBF) is widely used at an industrial scale for aluminum filtration. This filter consists of a packed bed of refractory particles [alumina tabs $(25 \mathrm{~cm})$ or alumina balls $(2$ $\mathrm{cm})$ ] through which the molten metal flows. The inclusions are deposited on the grains of the filter medium due to gravity, diffusion, surface forces, and direct interception. The inclusions larger than $30 \mu \mathrm{m}$ are filtered due to mechanical entrapment phenomena, while surface forces are responsible for removing inclusions smaller than $30 \mu \mathrm{m}$ from molten aluminum. Flow dynamics play a significant role in the transportation of smaller inclusions to the grain surfaces of filter media. Having a large surface area enables the DBF to trap inclusions much smaller than the pores of the filter bed. A DBF is suitable for continuous casting operations due to its long life cycle. However, the filters are costly to refurbish and work slowly at the end of their life. It is worth noting that the alumina tabs show high filtration efficiency compared with alumina balls at high melt velocities. ${ }^{49}$

Flotation and filtration processes are used after the remelting process to improve the quality of the recycled aluminum and can be considered under liquid aluminum treatments. 


\section{Salt Cake}

Salt cake/salt slag is the main waste generated from SAP, which contains a mixture of aluminum and metal oxides along with slag. When the salt cake is exposed to liquids, it releases toxic gases and soluble ions. ${ }^{50,51}$ It is considered as hazardous as it is highly flammable. Usually, rather than recycling or treating the slag cake, they are directly landfilled. For instance, around one million tons of salt cake was landfilled in the USA. ${ }^{52}$

In the rotary melting furnace process, the furnace is charged with metal scrap/dross and salt flux (generally up to $50 \%$ of the feed). The metal is protected by the salt and it further facilitates agglomeration and separation, resulting in improved metal recovery. ${ }^{53}$ In addition, the molten salt prevents the liquid metal from getting oxidized, and avoids metal contamination by absorbing the oxides and unwanted non-metallic substances. The aluminum metal and molten salt flux are tapped after the process, where the cooled flux along with the mixture of non-metallic components is called salt slag or salt cake. ${ }^{54}$ Salt slag contains $5-7$ wt.\% residual aluminum metal, 15-30 wt.\% aluminum oxide, 30-55 wt.\% sodium chloride, and 15-30 wt.\% potassium chloride and, depending upon the type of scrap added, carbides, nitrides, phosphides, and sulphides are also present. ${ }^{55}$

The salt cake is considered highly toxic, environmentally hazardous, and its disposal is problematic worldwide. Improper disposal of salt cakes while landfilling could lead to the reaction of its toxic metal ions with groundwater, resulting in environmental concerns. ${ }^{56}$ The highly toxic and poisonous gases such as $\mathrm{NH}_{3}, \mathrm{H}_{2} \mathrm{~S}, \mathrm{PH}_{3}$, and $\mathrm{CH}_{4}$ are formed when the salt cake interacts with water. Ammonia gas is produced from the hydrolysis of nitrides present in the salt cake: ${ }^{57-59}$

$$
\begin{gathered}
\mathrm{AlN}+3 \mathrm{H}_{2} \mathrm{O} \rightarrow \mathrm{NH}_{3}+\mathrm{Al}(\mathrm{OH})_{3} \\
\mathrm{AlN}+4 \mathrm{H}_{2} \mathrm{O} \rightarrow \mathrm{NH}_{4} \mathrm{OH}+\mathrm{Al}(\mathrm{OH})_{3}
\end{gathered}
$$

$$
\mathrm{NH}_{3}+\mathrm{H}_{2} \mathrm{O} \rightarrow \mathrm{NH}_{4} \mathrm{OH}
$$

Ammonia is highly soluble in water, increasing the $\mathrm{pH}$ value up to 9 and making the environment alkaline. At high $\mathrm{pH}$ values, the aluminum metal reacts with water and results in the formation of $\mathrm{H}_{2}$ and $\mathrm{Al}_{2} \mathrm{O}_{3}$ as shown in Eq. (17). The hot $\mathrm{H}_{2}$ reacts with air $\left(\mathrm{O}_{2}\right)$ and combustion takes place.

$$
2 \mathrm{Al}+3 \mathrm{H}_{2} \mathrm{O} \rightarrow 3 \mathrm{H}_{2}+\mathrm{Al}_{2} \mathrm{O}_{3}
$$

Methane evolution takes place when aluminum carbide present in the salt cake reacts with water:

$$
\mathrm{Al}_{4} \mathrm{C}_{3}+6 \mathrm{H}_{2} \mathrm{O} \rightarrow 3 \mathrm{CH}_{4}+2 \mathrm{Al}_{2} \mathrm{O}_{3}
$$

An increase in the pressure and heat under the landfill could also lead to the reaction of aluminum carbide with nitrogen gas present in the soil to generate aluminum cyanide, and with eventual hydrolysis of aluminum cyanide could form $\mathrm{HCN}$ :

$$
\begin{gathered}
2 \mathrm{Al}_{4} \mathrm{C}_{3}+6 \mathrm{~N}_{2}+9 \mathrm{C} \rightarrow 4 \mathrm{Al}(\mathrm{CN})_{3} \\
4 \mathrm{Al}(\mathrm{CN})_{3}+6 \mathrm{H}_{2} \mathrm{O} \rightarrow 12 \mathrm{HCN}+2 \mathrm{Al}_{2} \mathrm{O}_{3}
\end{gathered}
$$

From the above reactions, it is clear that the disposal of salt slags in hazardous landfills could pollute the groundwater (increasing $\mathrm{pH}$, $\mathrm{F}^{-}, \mathrm{Cl}^{-}$, and $\mathrm{NH}_{4}^{+}$). It is getting much harder to open new landfills due to increasing environmental pressures, and recycling/treating them could be the ultimate solution.

The $\mathrm{NaCl} / \mathrm{KCl}$ salts in the slag can be converted to value-added materials by employing the dechlorination process using weak-based, anion-exchange resin. ${ }^{60}$ The process chemistry is shown as follows:

Carbonation:

$$
\mathrm{R} . \mathrm{OH}+\mathrm{CO}_{2} \rightarrow \mathrm{R} . \mathrm{HCO}_{3}
$$

\section{Dechlorination:}

Table III. Filtration parameters affecting filtration efficiency

Filtration efficiency

Filtration parameter

Particles

Liquid flow

Filter medium

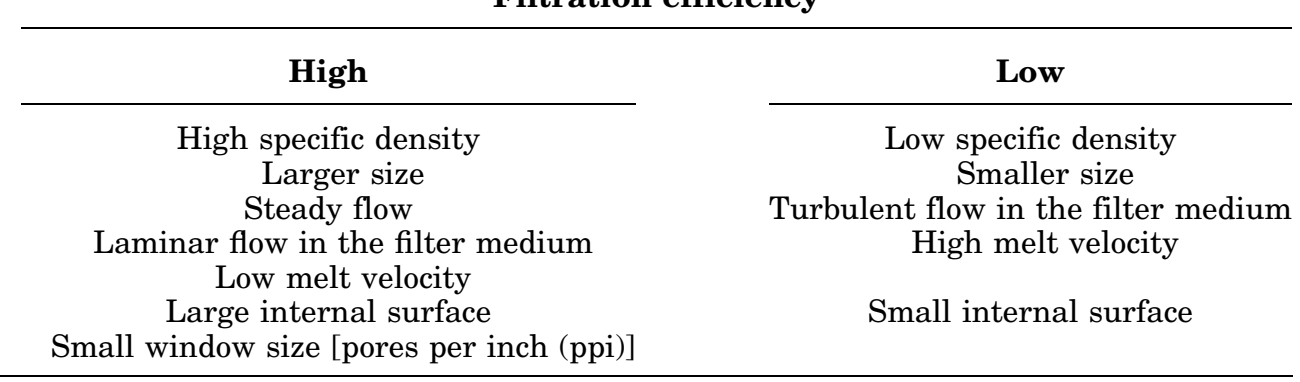




$$
R . \mathrm{HCO}_{3}+\mathrm{NaCl} / \mathrm{KCl} \rightarrow \mathrm{R} . \mathrm{Cl}+\mathrm{NaHCO}_{3} / \mathrm{KHCO}_{3}
$$

\section{Regeneration:}

$$
\mathrm{R} . \mathrm{Cl}+\mathrm{NH}_{4} \mathrm{OH} \rightarrow \mathrm{R} . \mathrm{OH}+\mathrm{NH}_{4} \mathrm{Cl}
$$

$\mathrm{R}$ is the complex cation group in the resin. It is a weak-base, anion exchange resin that is either the free base or hydroxide form. The active sites of the resin must be converted to bicarbonate form before implementing dechlorination of slag material. As shown in Eq. (21), the hydroxide-based resin is carbonated by treating with carbonated water to synthesize active bicarbonate groups. The resin ( $R$. $\mathrm{HCO}_{3}$ ) is then exhausted by an alkali metal chloride solution, as shown in Eq. (22). The exhausted R.Cl is regenerated to R.OH according to Eq. (23), using a $\mathrm{NH}_{4} \mathrm{OH}$ solution. The chloride ions' removal efficiency increases with a decrease in the ratio of slag solution to resin. The $\mathrm{NH}_{4} \mathrm{Cl}$ can be concentrated and sold as a chemical or can be further used to recover $\mathrm{NH}_{3}$ at an operating temperature of $200^{\circ} \mathrm{C}$ as shown below:

$$
\mathrm{NH}_{4} \mathrm{Cl}+\mathrm{H}_{2} \mathrm{O} \rightarrow \mathrm{NH}_{4} \mathrm{OH}+\mathrm{HCl}
$$

In this way, sodium- and potassium-based salts from the slag material can be recovered and could reduce the volume of materials going to the landfill. The level of highly water-soluble materials in the slag will be reduced so that cheaper and unlined landfills can be used. Moreover, the recovered salts can be reused in the processing smelters, or can be commercially sold.

The treatment process for the salt cake contains steps like (a) crushing and screening, (b) water leaching/ filtering, (c) gas elimination, and (d) evaporation/crystallization. Initially, the slag is crushed through milling, and metallic aluminum is separated by screening. Many companies process salt cake through wet milling, which would enrich the metallic concentrate and produce oxides and brine byproducts. ${ }^{61}$ The milled slag powder is then water leached, where a slurry is obtained which contains few grains of aluminum. These grains are removed utilizing a rotating screen and then finally dried. The remaining oxides slurry is filtered through a continuous vacuum belt filter, where the chlorides are intensely drained from the oxides cake. The obtained cake has a very low chloride content $(<0.2 \%)$ and can be employed in the construction industry as cement. The gases released

Table IV. A summary of various aluminum slag (dross) treatments

\section{Techniques used}

Plasma arc melting

Sintering and leaching

Sintering and hydraulic pressing

Plasma spray coating

Leaching

Sintering

Sintering

Leaching

Ball-milling, hydrolysis

Leaching

Leaching, sintering, and calcining

Leaching, hydrolysis
Remarks

Ref.

The plasma arc melting process was used to obtain $\gamma$-alumina powder. At a plasma level of $15 \mathrm{~kW}$, a maximum of $21 \%$ of raw dross could be converted into ultrafine $\mathrm{Al}_{2} \mathrm{O}_{3}$ powder About $90 \%$ of alumina was recovered from the dross using a soda roast-dilute caustic leaching route. All the chemicals used in this process can be recycled, hence cost-efficient

Hercynite $\left(\mathrm{FeAl}_{2} \mathrm{O}_{4}\right)$ was synthesized by using aluminum dross and iron at $1550^{\circ} \mathrm{C}$.

Results in avoiding the landfilling of the dross

$\mathrm{Al}_{2} \mathrm{O}_{3}$ and $\mathrm{MgAl}_{2} \mathrm{O}_{4}$ compounds were coated on tundish and Inconel substrates using plasma spray techniques. The implication to be used as a refractory coating (heat insulation). Unwanted AlN semi-conductive phase was removed

Aluminum dross treatment by leaching with $\mathrm{NaOH}$ and $\mathrm{H}_{2} \mathrm{SO}_{4}$ aqueous solutions resulting in the synthesis of tamarugite $\left[\mathrm{NaAl}\left(\mathrm{SO}_{4}\right)_{2} \cdot 6 \mathrm{H}_{2} \mathrm{O}\right]$. The applications for tamarugite have not yet been established

Magnesium aluminum titanate-based ceramics with high-temperature applications were synthesized by sintering aluminum dross and rutile ore at $1300^{\circ} \mathrm{C}$ for $6 \mathrm{~h}$.

Aluminum dross and coal fly ash were used to prepare mullite-based ceramics through sintering and acid leaching methods. At a sintering temperature of $1500^{\circ} \mathrm{C}$, high mullite content ceramics with good crystallinity were obtained

$\mathrm{Mg}-\mathrm{Al}, \mathrm{Ca}-\mathrm{Al}$, and $\mathrm{Zn}-\mathrm{Al}$ type layered double hydroxides synthesis by leaching aluminum dross with $\mathrm{HCl}$ and $\mathrm{NaOH}$ solution, mixing with magnetic stirring

$\mathrm{H}_{2}$ production by hydrolysis of ball-milled aluminum dross using tap water. $100 \%$ hydrogen yield

$\mathrm{Al}$ was separated from $\mathrm{Al}$ dross by using $\mathrm{HCl}$ leachate. The recovery rate was up to $22 \%$ $\mathrm{Al}_{2} \mathrm{O}_{3}$ and $\mathrm{MgAl}_{2} \mathrm{O}_{4}$ based refractory material was successfully synthesized by removing AlN through aqueous solution leaching. After a calcining process, the sample color turned to white from black

$\mathrm{Cl}, \mathrm{F}$, and AlN were removed by the hydrolysis process. AlN hydrolysis can be performed at room temperature, and the activation energy of AlN was $38.64 \mathrm{~kJ} \mathrm{~mol}^{-1}$. Therefore, the leaching residues containing $43.10 \%$ of aluminum can be used as a substitute for bauxite 
in the leaching process are burnt in a combustor, where the toxic ones are converted to inert gases and water. The heat produced during the combustion of pollutants is used as an energy source for the single or multistage crystallizer where the salts are recovered in the form of crystals. ${ }^{62}$

The non-metallic residues can be utilized in the following applications: ${ }^{62}$

- In the chemical industry: production of aluminum salts and hydrated aluminum oxide, epoxy resin mortar, inert load in polymers.

- In agriculture: fertilizers, artificial soil.

- In the metallurgical industry: synthetic steel refining slags to remove phosphorus, sulfur, and aluminum oxide from molten steel.

- In civil works: inert filling for constructions, mortar components, pavements.

- Mineral wool.

Table IV summarizes some of the processes used to recycle the aluminum slag through which valueadded materials can be recovered.

\section{CONCLUSION}

This paper discusses the recycling of aluminum as well as the utilization of salt slag generated from primary and secondary aluminum production. Various pre-refining steps and refining steps have been discussed in brief. Recycling aluminum can solve two issues at once: the demand for aluminum metal and the environmental issue. The refining processes need to be energy efficient and environmentally friendly. Remelting and fluxing are widely used industrially, and have a high metal yield, although these processes generate high volumes of environmentally hazardous salt slag. This would require treatment/utilization of the slag to avoid landfilling (which makes the environment alkaline). The Hoopes process requires more energy than the one required for primary aluminum production. On the other hand, SAP through electrolysis is promising, and a lot of work is being done in this area. The conventional treatment for salt slag recovery includes slag grinding, recovery of metal particles by sieving followed by leaching (with water) to dissolve the salt in water, then filtering and evaporation. The non-metallic residues can be landfilled or used to prepare cement, refractory, and ceramic applications, or be used in metallurgical and chemical industries. This could eventually reduce the landfilling cost and would be environmentally friendly.

\section{CONFLICT OF INTEREST}

On behalf of all authors, the corresponding author states that there is no conflict of interest.

\section{ACKNOWLEDGEMENTS}

The reported study was funded by RFBR according to the research project No 18-29-24122.

\section{FUNDING}

Open Access funding enabled and organized by Projekt DEAL.

\section{OPEN ACCESS}

This article is licensed under a Creative Commons Attribution 4.0 International License, which permits use, sharing, adaptation, distribution and reproduction in any medium or format, as long as you give appropriate credit to the original author(s) and the source, provide a link to the Creative Commons licence, and indicate if changes were made. The images or other third party material in this article are included in the article's Creative Commons licence, unless indicated otherwise in a credit line to the material. If material is not included in the article's Creative Commons licence and your intended use is not permitted by statutory regulation or exceeds the permitted use, you will need to obtain permission directly from the copyright holder. To view a copy of this licence, visit $h$ ttp://creativecommons.org/licenses/by/4.0/.

\section{REFERENCES}

1. H. Kvande. Fundamentals of Aluminium Metallurgy: Production, Processing, and Applications, ed. R. Lumley (Cambridge, Woodhead Publishing Limited, 2010), pp. 4969 (2010).

2. M. Gautam, B. Pandey, M. Agrawal, Environmental Carbon Footprints, ed. S. S. Muthu (Oxford, Butterworth-Heinemann, 2018), pp. 197-228.

3. H. Kvande, and W. Haupin, JOM 53, 29. (2001).

4. Bureau of International Recycling (BIR) Annual report 2019, link: https://www.bir.org/publications/annual-reports/ download/648/1000000235/36?method=view (Accessed on 3 March 2021).

5. A.S. Yasinskiy, S.K. Padamata, P.V. Polyakov, and A.V. Shabanov, Non-Ferrous Met. 2020(1), 15. (2020).

6. J. Green, Aluminum Recycling and Processing for Energy Conservation and Sustainability, ed. J. Green (ASM International, 2007), p. 220.

7. G Gaustada, E. Olivetti, R. Kirchain, Resour., Conserv. Recycl. 58,79 (2012).

8. M. Kondo, H. Maeda, and M. Mizuguchi, JOM 42, 36. (1990).

9. European Aluminium Association, link: https://www.euro pean-aluminium.eu/policy-areas/recycling-circular-econo my/ (Accessed on 3 March 2021).

10. G. Gaustad, E. Olivetti, and R. Kirchain, J. Ind. Ecol. 14, 286. (2010).

11. S.K. Das, Light Metals, ed. T.J. Galloway, (San Antonio, TMS, 2006), p. 911.

12. A. Gesing, JOM 56, 18. (2004).

13. M.A. Reuter, K. Heiskanen, U. Boin, A. Van Schaik, E. Verhoef, Y. Yang, and G. Georgalli, The Metrics of Material and Metal Ecology: Harmonizing the Resource, Technology and Environmental Cycles, 1st edn. (Elsevier, Amsterdam, 2005), pp 373-390.

14. S. Capuzzi, and G. Timelli, Metals 8, 249. (2018).

15. D.B. Spencer, JOM 57, 46. (2005).

16. M.E. Schlesinger, Aluminum Recycling, 1st edn. (CRC Press, Boca Raton, 2007), pp 71-75.

17. G.H. Nijhof, Resou. Conserv. Recycl. 10, 161. (1994).

18. J. Ruan, L. Dong, J. Zheng, T. Zhang, M. Huang, and Z. Xu, Waste Manag. 60, 84. (2017).

19. P. Werheit, C. Fricke-Begemann, M. Gesing, and R. Noll, J. Anal. At. Spectrom. 26, 2166. (2011).

20. R. Noll, C. Fricke-Begemann, S. Connemann, C. Meinhardt, and V. Sturm, J. Anal. At. Spectrom. 33, 945. (2018). 
21. S. Piorek, Mater. Today: Proc. 10, 348. (2019).

22. R. Schramm, Phys. Sci. Rev. 1, 20160061. (2016).

23. S. Eggen, K. Sandaunet, L. Kolbeinsen, A. Kvithyld, Light Metals, ed. A. Tomsett, (San Diego, TMS, 2020), p. 1091.

24. K. Nakajima, O.Takeda, T. Miki, K, Matsubae, S. Nakamura, T. Nagasaka, Environ. Sci. Technol. 44, 5594 (2010).

25. T.A. Utigard, K. Friesen, R.R. Roy, J. Lim, A. Silny, and C. Dupuis, JOM 50, 38. (1998).

26. P.N. Crepeau, M.L. Fenyes, and L.J. Jeanneret, Mod. Cast. 82, 28. (1992).

27. Y. Xiao, and M.A. Reuter, Miner. Eng. 15, 963. (2002).

28. Y.S. Kim, E.P. Yoon, K.T. Kim, W.J. Jung, and D.H. Jo, J. Kor. Fou. Soc. 20, 39. (2000).

29. R.D. Peterson, Second international symposium-recycling of metals and engineered materials, ed. J.H. Van Linden, L. Donald, J. Stewart, Y. Sahai, (Pittsburgh, TMS, 1990), p. 69.

30. J.A.S. Tenorio, and D.C.R. Espinosa, J. Light. Met. $2,89$. (2002).

31. R.R. Roy, and Y. Sahai, Mater. Trans. 38, 995. (1998).

32. M. Gokelma, I. Meling, E. Soylu, A. Kvithyld, G. Tranell, Light Metals, ed. C. Chesonis, (San Antonio, TMS, 2019), p. 1359.

33. S. Huan, Y. Wang, K. Liu, J. Peng, Y. Di, J. Electrochem. Soc. 167, 103503 (2020).

34. S. Huan, Y. Wang, J. Peng, Y. Di, B. Li, L. Zhang, Miner. Eng. 154, 106386 (2020).

35. A.I. Kahveci, A. Unal, Recycling of Metals and Engineered Materials, ed. D.L. Stewert, J.C. Daley, R.L. Stephens, (TMS, 2000), p. 919.

36. D.C. Curtolo, S. Friedrich, D. Bellin, G.S. Nayak, and B. Friedrich, Metals 7, 341. (2017).

37. S.Venditti, D. Eskin, A. Jacot, Light Metals, ed. A. Tomsett, (San Diego, TMS, 2020), p. 1110.

38. R.Y. Lin, and M. Hoch, Metall. Trans. A 20A, 1785. (1989).

39. G.K. Sigworth, Essential Readings in Light Metals, (TMS, 2016), p. 226.

40. O. Mirgaux, D. Ablitzer, E. Waz, and J.P. Bellot, Metall. Mater. Trans. B. 40B, 363. (2009).

41. G.K. Sigworth, E.M. Williams, D.C. Chesonis, Essential Readings in Light Metals, (TMS, 2016), p. 65.

42. H. Gorner, M. Syvertsen, E.J. Ovrelid, T.A. Engh, Light Metals, ed. H. Kvande, (San Francisco, TMS, 2005), p. 939.

43. M. Syversen, A. Kvithyld, S. Bao, A. Nordmark, A. Johansson, Light Metals. ed. J. Grandfield, (San Diego, TMS, 2014), p. 1041.

44. N.J. Keegam and J.M. McCollum, Light Metals, ed. E.R. Cutshall, (San Diego, TMS, 1992), p. 1086.

45. C. Voigt, E. Jackel, F. Taina, T. Zienert, A. Salomon, G. Wolf, C.G. Aneziris, and P.L. Brun, Metall. Mater. Trans. B. 48B, 497. (2017).

46. E. Laé, H. Duval, C. Rivière, P. Le Brun, J.-B. Guillot, Essential Readings in Light Metals, (TMS, 2016), p. 285.

47. L.J. Gauckler, M.M. Waeber, C. Conti, M. Jacob-Duliere, Essential Readings in Light Metals, (TMS, 2016), p. 251.

48. L.N.W. Damoah, and L. Zhang, Metall. Mater. Trans. B. 41B, 886. (2010).

49. R. Mutharasan, D. Apelian, and C. Romanowski, JOM 33, 12-18. (1981).
50. T.W. Unger, and M. Beckmann, Light Metals (TMS, San Diego, 1992), p 1159.

51. G.V. Calder and T.D. Stark, J. Hazard., Toxic Radioact. Waste, 14, 258 (2010).

52. TAA, Aluminum-The Element of Sustainability, (The Aluminum Association, Washington D. C., 2011),pp. 70

53. N. Unlu, M.G. Drouet, Resour., Conserv. Recycl. 36, 61 (2002).

54. L. Zhang, Light Metals, ed. T.J. Galloway, (San Antonio, TMS, 2006), p. 931.

55. J.Y. Hwang, X. Huang, and Z. Xu, J. Min. Mat. Charact. Eng. 5, 47. (2006).

56. B.R. Das, B. Dash, B.C. Tripathy, I.N. Bhattacharya, and S.C. Das, Miner. Eng. 20, 252. (2007).

57. M.C. Shinzato, and R. Hypolito, Waste Manage. 25, 37. (2005).

58. G.V. Calder, and T.D. Stark, Pract. Period. Hazard. Tox. Radioact. Waste Manag. 14, 258. (2010).

59. A. Gil, Ind. Eng. Chem. Res. 44, 8852. (2005).

60. A.C. Sheth, K.D. Parks, and S. Parthasarathy, JOM 48, 32. (1996).

61. D. Yerushalmi, Light Metals: Proceedings of Sessions, (TMS, 1992), p. 1083.

62. P.E. Tsakiridis, J. Hazard. Mater. 217-218, 1. (2012).

63. R. Saravanakumar, K. Ramachandran, L.G. Laly, P.V. Ananthapadmanabhan, and S. Yugeswaran, Waste Manag. 77, 565. (2018)

64. A.K. Tripathy, S. Mahalik, C.K. Sarangi, B.C. Tripathy, K. Sanjay, and I.N. Bhattacharya, Miner. Eng. 137, 181. (2019).

65. C. Chobtham, and S. Kongkarat, Mater. Sci. Forum. 977, 223. (2020).

66. P. Ramaswamy, P. Tilleti, R. Pinto, S. Ranjith, and J. Benjamin, Mater. Today Proc. 22, 1285. (2020).

67. A. Meshram, A. Jain, D. Gautam, and K.K. Singh, J. Environ. Manag. 232, 978. (2019).

68. E.M.M. Ewais, and N.H.A. Besisa, Mater. Des. 141, 110. (2018).

69. C.T. Foo, M.A.M. Salleh, K.K. Ying, and K.A. Matori, Ceram. Int. 45, 7488. (2019).

70. N. Murayama, I. Maekawa, H. Ushiro, T. Miyoshi, J. Shibata, and M. Valix, Int. J. Miner. Process. 110-111, 46. (2012).

71. E. David, and J. Kopac, J. Hazard. Mater. 209-210, 501. (2012).

72. Q. Yang, Q. Li, G. Zhang, Q. Shi, and H. Feng, Hydrometallurgy 187, 158. (2019).

73. P. Ramaswamy, S. Ranjit, S. Bhattacharjee, and S.A. Gomes, Mater. Today Proc. 19, 670. (2019).

74. H. Lv, H. Zhao, Z. Zuo, R. Li, and F. Liu, J. Mater. Res. Technol. 9, 9735. (2020).

Publisher's Note Springer Nature remains neutral with regard to jurisdictional claims in published maps and institutional affiliations. 